\title{
DESDOBRAMENTO DA FUNÇÃO QUALIDADE (QFD) NO DESENVOLVIMENTO DE PROJETO DE TREINAMENTO: ESTUDO EXPLORATÓRIO PARA SERVIÇO
}

\section{QUALITY FUNCTION DEPLOYMENT (QFD) IN THE DEVELOPMENT OF TRAINING PROJECTS: AN EXPLORATORY STUDY FOR SERVICE}

\author{
Francisco José Dias Júnior* E-mail: xyko.dias1953@hotmail.com \\ Jorge Muniz Junior**E-mail: jorgemuniz@feg.unesp.br \\ Fernando Antônio Elias Claro*E-mail: fernandoclaro@uol.com.br \\ Davi Noboru Nakano**E-mail: dnnakano@usp.br \\ *Universidade de Taubaté, Taubaté, SP \\ **Universidade Estadual Paulista, UNESP, Pedregulho Guaratinguetá, SP \\ ${ }^{* * *}$ Escola Politécnica, Butantã, SP
}

\begin{abstract}
Resumo: O treinamento é relevante na preparação de funcionários. O Desdobramento da Função Qualidade (QFD) tem se mostrado como um método eficaz para traduzir sistematicamente as necessidades dos clientes em especificações de projetos. Esta pesquisa apresenta a utilização do método QFD em uma aplicação de desenvolvimento de projeto de treinamento. Trata-se de uma pesquisa qualitativa realizada em no setor de treinamento de uma empresa de serviços de grande porte. Os resultados obtidos mostram que a utilização do QFD é uma alternativa eficaz para os gestores elaborarem ou melhorarem seus projetos de treinamento.
\end{abstract}

Palavras-chave: Serviço. Treinamento. Desdobramento da Função Qualidade.

Abstract: Training is important in preparing employees. The Quality Function Deployment (QFD) is an effective method to systematically translate customer requirements into project specifications. This study presents the use of QFD method in development of training project. It is a qualitative research conducted in the industry services company. The results show that the use of QFD is an effective alternative for managers to develop or improve their training projects.

Keywords: Service. Training. Quality Function Deployment.

\section{INTRODUÇÃO}

Devido ao contato estreito, interação e situações inusitadas com o cliente, a produção de serviço se torna mais dependente da competência do prestador e de sua transformação em ação para atendimento do cliente (KOTLER, 1998). Profissionais bem treinados contribuem na melhoria desse desempenho, o que é mais evidente na produção de serviço.

Atualmente, a área de treinamento tem-se utilizado das diretrizes da norma NBR ISO 10015 (2001), que, entre outras orientações, propõe: (a) identificar e 
analisar as necessidades de treinamento; (b) projetar e planejar o treinamento; (c) executar o treinamento; (d) avaliar os resultados do treinamento; (e) monitorar; e (f) melhorar o processo de treinamento de modo a atingir seus objetivos. No entanto, observa-se que não é comum a área de treinamento empregar técnicas de gestão.

Campos e Guimarães (2008), por exemplo, adaptaram a norma supracitada em um roteiro prescritivo de implantação para projetos de treinamento. Embora haja considerações relativas à identificação e à análise das necessidades, são negligenciados aspectos do método para se capturarem tais requisitos, aumentando o distanciamento entre a operação e o treinamento em sala de aula. É importante que haja atenção na identificação das demandas que caracterizem um treinamento eficaz, ou seja, ouvir o cliente em sua linguagem.

Dessa forma, apresentam-se, então, as questões: Como traduzir as demandas de treinamento dos funcionários em políticas de treinamento? Qual é o método que se mostra mais eficaz para se obterem as prioridades técnicas e então tratá-las? Qual é o método que estabelece um comparativo com a concorrência de modo a direcionar as ações?

O presente trabalho tem como objetivo apresentar a utilização do método Desdobramento da Função Qualidade (QFD) em uma aplicação de desenvolvimento de projeto de treinamento. Este estudo foi realizado em uma empresa de serviços relacionados à tecnologia da informação e é delimitado ao desenvolvimento de treinamento para técnicos de campo.

Na Seção 2 apresenta-se a revisão teórica, utilizou-se de análise bibliométrica na base Web of Science, sendo consultados artigos entre 2001 e 2011. Tal análise indicou que o presente trabalho representa uma contribuição original. Na Seção 3 tem-se o procedimento metodológico, na Seção 4 os resultados obtidos e por fim na Seção 5 são apresentadas as conclusões.

\section{FUNDAMENTAÇÃO TEÓRICA}

Nesta seção são apresentados a Análise Bibliométrica internacional e nacional, conceitos referentes aos Fundametos de Serviços, Fundamentos de Treinamento e Desdobramento da Função Qualidade (QFD), com ênfase na aplicação em serviços. 


\subsection{Análise Bibliométrica}

O tema QFD continua um tema relevante de pesquisa, como indica a Tabela 1 publicada por Carnevalli e Miguel (2007):

Tabela 1 - Os quatorze periódicos que mais publicaram artigos sobre QFD

\begin{tabular}{|c|c|c|c|c|c|c|c|c|}
\hline Periódico & 2000 & 2001 & 2002 & 2003 & 2004 & 2005 & 2006 & Total \\
\hline $\begin{array}{l}\text { Benchmarking: An International } \\
\text { Journal }\end{array}$ & 2 & & & & & 1 & 1 & 4 \\
\hline $\begin{array}{l}\mathrm{CE} \text { - Concurrent Enginnering: } \\
\text { Research and Aplications }\end{array}$ & & & & & & 3 & 3 & 6 \\
\hline Computers \& Industrial Engineering & & & 2 & 1 & 1 & 1 & & 5 \\
\hline $\begin{array}{l}\text { European Journal of Operational } \\
\text { Research }\end{array}$ & 1 & & 2 & & & & 3 & 6 \\
\hline Gestão \& Produção & & & & & 1 & 1 & 1 & 3 \\
\hline Industrial Management \& Data System & & 1 & & 1 & 1 & 1 & & 4 \\
\hline $\begin{array}{l}\text { International Journal of Operations \& } \\
\text { Production Management }\end{array}$ & 1 & 1 & 1 & & & & & 3 \\
\hline $\begin{array}{l}\text { International Journal of Production } \\
\text { Econonics }\end{array}$ & 3 & 1 & 1 & 1 & 1 & & 1 & 8 \\
\hline $\begin{array}{l}\text { International Journal of Quality \& } \\
\text { Realiabilily Managemenl }\end{array}$ & & 2 & 3 & 11 & 8 & 7 & 2 & 33 \\
\hline Journal of lntelligent Manufacturing & 1 & 2 & 1 & & & & & 4 \\
\hline Managerial Auditing Journal & 2 & & 2 & & & & & 4 \\
\hline Managing Service Quality & 2 & & & & 1 & & & 3 \\
\hline $\begin{array}{l}\text { Produção Online (Obs.: Períodico } \\
\text { incluído pelo autor) }\end{array}$ & & & & 1 & & 1 & & 2 \\
\hline Quality Progress & 1 & 1 & & 1 & & 2 & & 5 \\
\hline Total & 13 & 8 & 12 & 16 & 13 & 17 & 11 & 90 \\
\hline
\end{tabular}

Fonte: Adaptado de Carnevalli e Miguel (2007)

A análise bibliométrica na base Web of Science, utilizando-se como tópicos de busca: QFD, Service e Training, identificou 8 artigos entre os anos de 2001 a 
2011. A análise indica que o tema (combinação de QFD, Service e Training) é pouco explorado, o que pode representar uma oportunidade de pesquisa. O Quadro 1 indica o resumo dos 8 trabalhos e sua relevância por meio do número de vezes que foi citado.

Quadro 1 - Trabalhos internacionais - tema QFD, Serviço e Treinamento 2001-2011

\begin{tabular}{|c|c|c|c|}
\hline \# & $\begin{array}{l}\text { Autor(es) } \\
\text { Ano }\end{array}$ & Objetivo & $\begin{array}{l}N^{\circ} \text { de } \\
\text { citações no } \\
\text { ano }\end{array}$ \\
\hline 1 & $\begin{array}{l}\text { Kuo et al } \\
(2011)\end{array}$ & $\begin{array}{l}\text { Avaliar a qualidade dos serviços ambulatoriais de pacientes } \\
\text { idosos em Taiwan }\end{array}$ & \\
\hline 2 & $\begin{array}{l}\text { Lick et al } \\
(2011)\end{array}$ & $\begin{array}{l}\text { Determinar as taxas de sobrevivência de parada cardíaca } \\
\text { relacionadas a implementação do programa desenvolvido em } \\
\text { hospitais dos Estados Unidos da América }\end{array}$ & 13 \\
\hline 3 & $\begin{array}{l}\text { Celletti et } \\
\text { al (2010) }\end{array}$ & $\begin{array}{l}\text { Avaliar a contribuição dos agentes comunitários com foco na } \\
\text { identificação dos elementos críticos de um ambiente que garanta } \\
\text { prestação de serviços de qualidade de forma sustentável. O } \\
\text { estudo foi realizado no Brasil, Etiópia, Malawi, Namíbia e Uganda. }\end{array}$ & 5 \\
\hline 4 & $\begin{array}{l}\text { Engelke et } \\
\text { al (2009) }\end{array}$ & $\begin{array}{l}\text { Melhorar o processo de projeto do serviço de processamento de } \\
\text { imagem que faz uso de redes sem fio }\end{array}$ & \\
\hline 5 & $\begin{array}{l}\text { Justham et } \\
\text { al (2008) }\end{array}$ & $\begin{array}{l}\text { Usar a matriz de planejamento (HOQ) do produto da "Casa da } \\
\text { Qualidade" para entender as necessidades dos usuários do } \\
\text { sistema em todo o desenvolvimento de um novo sistema de } \\
\text { treinamento para o jogo críquete }\end{array}$ & 7 \\
\hline 6 & $\begin{array}{l}\text { Chou } \\
(2004)\end{array}$ & $\begin{array}{l}\text { Aplicar as técnicas do QFD para avaliar a qualidade do serviço de } \\
\text { ensino de graduação em enfermagem em Taiwan a partir da } \\
\text { perspectiva dos estudantes de enfermagem }\end{array}$ & 1 \\
\hline 7 & $\begin{array}{l}\text { Woodford } \\
\text { (2004) }\end{array}$ & $\begin{array}{l}\text { Explorar alguns dos principais desafios que os formuladores de } \\
\text { políticas têm de superar na transição de um serviço estatal } \\
\text { (serviço de saúde veterinária) a de outro constituído na parceria } \\
\text { com o setor privado }\end{array}$ & \\
\hline 8 & $\begin{array}{l}\text { Lee; Lo } \\
(2003)\end{array}$ & $\begin{array}{l}\text { Apresentar uma aplicação do QFD associado à outras } \\
\text { ferramentas no planejamento estratégico do novo currículo para o } \\
\text { desenvolvimento de estratégias no ensino profissional com base } \\
\text { nos Critérios de Educação de 1999, aprovada a partir do Prêmio } \\
\text { Qualidade Malcolm Baldrige National }\end{array}$ & Nenhuma \\
\hline
\end{tabular}

Fonte: Web of Science

Os artigos mais citados - Kuo et al (2011), e Lick et al (2011) - não tratam de projeto de treinamento, indicando a relevância deste trabalho. O artigo mais alinhado com este trabalho - Chou (2004) - tem apenas uma citação mostrando que há espaço para outros artigos com este foco em serviço de treinamento.

Entre os anos de 2005-2007 não houve publicações que contivesse os três tópicos. Em 2008 houve uma retomada de publicações sobre esse trinômio com pico em 2011, o que pode indicar uma atenção a temas como o abordado no presente artigo. 


\subsection{Fundamentos de Serviços}

Kotler (1998, p. 412) define serviço como "qualquer ato ou desempenho que uma parte possa oferecer à outra e que seja essencialmente intangível e não resulte na propriedade de nada".

Segundo Gianesi e Corrêa (1996), a administração de serviços é um elemento importante na estratégia das empresas, sobretudo, quando o composto produto/serviços traz uma alta participação dos serviços na tarefa de fornecerem alto valor para os clientes.

\subsection{Fundamentos de Treinamento}

Para Bonfim (2004) o processo de treinamento nasceu com a transmissão de novos conhecimentos, novas tecnologias e transmissão desses conhecimentos e habilidades para seus semelhantes desde tempos remotos.

A perspectiva taylorista revelou que, no contexto da empresa, o treinamento surge para solucionar dificuldades que já se faziam presentes no início da industrialização. Fontes (1995 apud BONFIM, 2004, p. 27) "afirma que, com o avanço tecnológico que se processa desde o antigo sistema industrial, o treinamento cada vez mais tem contribuído no processo de especialização do operário".

Drucker (2002) menciona Taylor como sendo o estudioso do trabalho; antes dele, pouco se acreditava que fosse possível produzir algo de qualidade que não fosse feito por pessoa especializada como os artesãos. Além disso, ao estudar minuciosamente o trabalho e dividi-lo em partes menores a ponto de ser possível ensinar qualquer pessoa a realizá-lo, Taylor estava dando início ao treinamento sistemático, e a partir daí a produtividade deu grande salto a ponto de ganhar, segundo Drucker (2002), a categoria de revolução da produtividade.

Borges-Andrade (2002 apud ABBAD e PILATI, 2005) define treinamento como a aquisição sistemática de competências (conhecimentos, habilidades, atitudes), regras e conceitos que resultam em um aumento do desempenho no trabalho. 


\subsection{Desdobramento da Função Qualidade (QFD)}

QFD é um método para: (a) transformar demandas do usuário em funções de qualidade do projeto; (b) desdobrar as funções que dão forma à qualidade; (c) desdobrar métodos de qualidade do projeto em subsistemas e em componentes; e finalmente (d) obter os elementos específicos do processo de manufatura ou serviço.

Cheng (2007) descreve que a busca pela qualidade total se inicia com a concepção do projeto, segue com a aproximação entre a Qualidade Exigida dos clientes e a Qualidade do Produto e Serviço recebido, passando pela Qualidade de Especificações e Qualidade de Fabricação do Produto.

\subsubsection{A Casa da Qualidade}

Para Tapke et al. (2009), há muitas formas diferentes da Casa da Qualidade (Figura 1), mas sua capacidade de ser adaptada às exigências de um problema particular a torna um sistema forte e confiável para se usar. Seu formato geral é composto por seis principais componentes, os quais incluem: (a) exigências dos clientes; (b) requisitos técnicos; (c) matriz de planejamento; (d) matriz de interrelação; (e) matriz de correlação técnica; (f) seção técnica de prioridades/benchmarks e metas.

Figura 1 - Casa da Qualidade

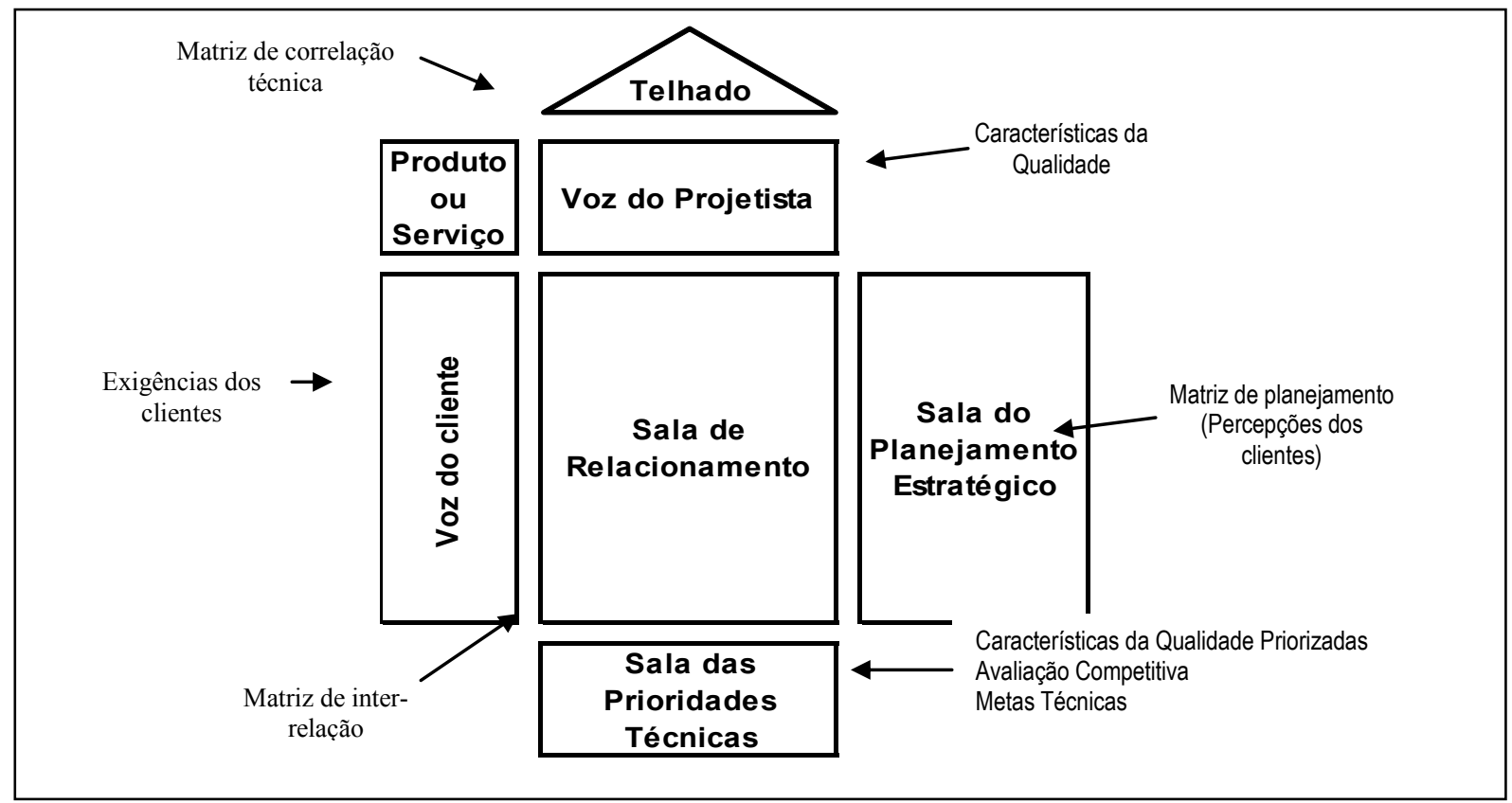

Fonte: Adaptado de Sharma e Rawani (2007) e Tapke et al (2009) 
Considerando-se que o método assume o formato de uma casa, é comum a nomeação para cada compartimento de acordo com a função primordial que desempenha (Figura 1).

\subsubsection{Fases do QFD}

Definição do objetivo - Guinta e Praizler (1993, p. 31) relatam que a definição do objetivo "[...] mantém a equipe concentrada em requisitos específicos do cliente, delineando o raio de ação de cada esforço do QFD de modo que cada equipe cuide de uma única tarefa controlável [...]".

A voz do cliente - Uma forma útil do processo de ouvir o cliente é o modelo de Kano citado por Cheng (2007). Esse modelo propõe uma classificação dos diversos itens de qualidade de produto conforme a percepção dos clientes.

Após definir o objetivo, conhecer a natureza dos requisitos e formar um grupo de clientes, o próximo passo é ouvir o cliente, que consiste em:

(...) prestar atenção aos requisitos. Os japoneses chamam esses requisitos de qualidades desejadas pelos clientes. No QFD, essas qualidades tornam-se itens de uma lista de quês. Pense em cada um desses itens como o que o cliente deseja - cada uma das características do produto, serviço ou problema (GUINTA e PRAIZLER, 1993, p. 41).

Essa lista de qualidades é formatada e ganha o aspecto de tabela; por esse motivo, alguns autores a chamam de tabela de Qualidade Exigida. A tabela desempenha um papel fundamental, pois é considerada a unidade elementar do QFD. Um exemplo pode ser visto no Quadro 2 
Quadro 2 - Exemplo de tabela de Desdobramento da Função Qualidade Exigida

\begin{tabular}{|c|c|c|}
\hline Nível 1 & Nível 2 & Nível 3 \\
\hline \multirow{10}{*}{1 Ensino eficaz } & \multirow{3}{*}{ 1.1 Bom instrutor } & 1.1.1 Instrutor transmite entusiasmo pelo assunto \\
\hline & & 1.1.2 Instrutor esclarece bem as dúvidas \\
\hline & & 1.1.3 Instrutor prende a atenção dos participantes \\
\hline & \multirow{4}{*}{$\begin{array}{l}1.2 \text { Material didático de } \\
\text { boa qualidade }\end{array}$} & 1.2.1 Material de fácil entendimento \\
\hline & & 1.2.2 Material que estimule maior participação \\
\hline & & 1.2.3 Material de fácil utilização \\
\hline & & 1.2.4 Material agradável aos quatro sentidos \\
\hline & \multirow{3}{*}{$\begin{array}{l}\text { 1.3 Bom conteúdo } \\
\text { programático }\end{array}$} & 1.3.1 Conteúdo adequado \\
\hline & & 1.3.2 Bom equilíbrio entre teoria $\mathrm{x}$ prática \\
\hline & & 1.3.3 Boa distribuição das atividades do curso \\
\hline \multirow{2}{*}{$\begin{array}{l}2 \text { Aula } \\
\text { agradável }\end{array}$} & \multirow{2}{*}{$\begin{array}{l}2.1 \text { Ambiente físico } \\
\text { agradável aos quatro } \\
\text { sentidos }\end{array}$} & 2.1.1 Ambiente com temperatura agradável \\
\hline & & 2.1.2 Ambiente com boa iluminação \\
\hline
\end{tabular}

Fonte: Adaptado de Cheng (2007)

O planejamento da qualidade - Após ouvir o cliente e elaborar a tabela da Qualidade Exigida, o próximo passo é planejar a qualidade. Para tanto, levantam-se os seguintes dados de cada item de qualidade exigida: (a) grau de importância; (b) grau de desempenho; (c) nível de desempenho da concorrência; (d) plano de qualidade; (e) índice de melhoria; (f) argumento de venda; (g) peso absoluto; e (h) peso relativo. Para quantificar cada um dos itens que determinam o grau de prioridade é útil usar a escala de Likert.

O Grau de Importância (GI), Desempenho da Concorrência (DC), são valores obtidos por meio de instrumentos de coleta de dados (ex. questionários) que são aplicados para um grupo de clientes; já o Índice de Melhoria (IM) é o resultado de cálculo por meio de uma equação $I M=\frac{P Q}{G D}$; o Plano de Qualidade (PQ) é obtido, por consenso, a partir do grupo de projeto. Para isto, o grupo de projeto analisa criticamente cada Qualidade Exigida e define uma pontuação (exemplos de 1 a 5). Quanto ao Argumento de Venda (AV), este é fruto de análise de outro grupo (é comum ser do departamento de marketing), que analisa o quanto uma determinada Qualidade Exigida pode alavancar a venda do produto em estudo. 
A voz do projetista - Uma vez identificados e quantificados os itens de Qualidade Exigida, o projetista tem os elementos para definir as Características da Qualidade (em algumas publicações chamadas de Requisitos Técnicos), que de alguma forma são capazes de satisfazerem os itens de Qualidade Exigida.

Conforme a Figura 1, os itens de Qualidade Exigida são dispostos em linhas e as Características da Qualidade em colunas; essa configuração é como uma matriz, podendo estabelecer relações entre as duas tabelas.

Cheng (2007) ressalta que essa matriz interliga dois mundos por uma relação de causa e efeito; esses dois mundos são o do cliente e o da tecnologia. O mundo do cliente é representado pela Tabela de Desdobramento da Qualidade Exigida e Qualidade Planejada. Já o mundo da tecnologia é representado pelo projeto básico formado, por sua vez, pela Tabela de Desdobramento das Características da Qualidade e Qualidade Projetada.

Cheng busca simplificar afirmando que:

pode-se considerar que a Matriz da Qualidade possui significado mais profundo, isto é, "a conversão do mundo dos clientes para o mundo da tecnologia; ou ainda, em linguagem mais prática", a tradução da Voz dos Clientes em informações do Projeto Básico (2007, p. 135).

Ainda o autor argumenta que a tabela das Características da Qualidade (no caso de serviço, é chamada de Elementos da Qualidade) é obtida pelo processo de extração, ou seja, os elementos de uma tabela são obtidos a partir dos elementos de outra tabela. Portanto, para cada Qualidade Exigida devem-se identificar as Características de Qualidade, que podem ser medidas no produto final.

Desse modo, para cada item de Qualidade Exigida, Cheng (2007, p. 138) recomenda esse questionamento: "Quais são as características do produto que medem tecnicamente o item de qualidade exigida?". Procedendo desta forma é possível capturar as características da qualidade que medem e satisfazem as qualidades exigidas. Como exemplo veja a Figura 2. 
Figura 2 - Exemplo de obtenção das Características da Qualidade

\begin{tabular}{|c|c|c|c|c|c|c|c|c|c|c|}
\hline & & 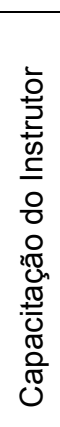 & 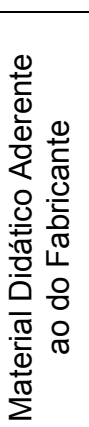 & 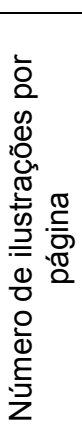 & 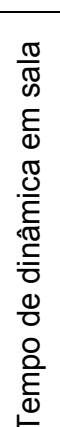 & 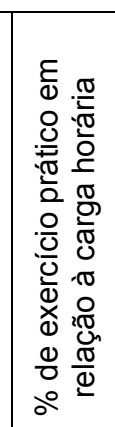 & 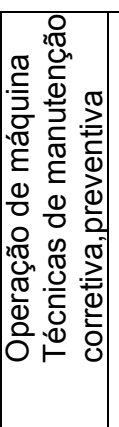 & 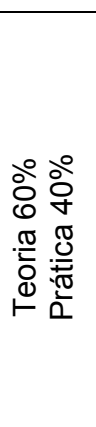 & $\begin{array}{l}0 \\
\frac{0}{0} \\
\frac{0}{0} \\
\frac{0}{0} \\
\frac{0}{0} \\
\overline{0} \\
0 \\
\frac{1}{2}\end{array}$ & 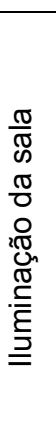 \\
\hline $\begin{array}{l}\text { Qualidade Exigida (Nível } \\
\text { 3) }\end{array}$ & Meta & $\uparrow$ & $=$ & $=$ & $\uparrow$ & $=$ & $=$ & $=$ & $=$ & $=$ \\
\hline \multicolumn{11}{|c|}{$\begin{array}{l}\text { Instrutor transmite entusiasmo pelo } \\
\text { assunto }\end{array}$} \\
\hline \multicolumn{11}{|c|}{ Instrutor esclarece bem as dúvidas } \\
\hline \multicolumn{11}{|c|}{$\begin{array}{l}\text { Instrutor prende a atenção dos } \\
\text { participantes }\end{array}$} \\
\hline \multicolumn{11}{|c|}{ Material de fácil entendimento } \\
\hline \multicolumn{11}{|c|}{$\begin{array}{c}\text { Material que estimule maior } \\
\text { participação }\end{array}$} \\
\hline \multicolumn{11}{|c|}{ Material de fácil utilização } \\
\hline \multicolumn{11}{|c|}{$\begin{array}{c}\text { Material agradável aos quatro } \\
\text { sentidos }\end{array}$} \\
\hline \multicolumn{2}{|c|}{ Conteúdo adequado } & & & & \multicolumn{5}{|c|}{ Sala de Relacionamento } & \\
\hline \multicolumn{11}{|c|}{ Bom equilíbrio entre teoria e prática } \\
\hline \multicolumn{11}{|c|}{$\begin{array}{l}\text { Boa distribuição das atividades do } \\
\text { curso }\end{array}$} \\
\hline \multicolumn{11}{|c|}{$\begin{array}{c}\text { Ambiente com temperatura } \\
\text { agradável }\end{array}$} \\
\hline Ambiente com boa ilumi & ção & & & & & & & & & \\
\hline
\end{tabular}

Fonte: Elaborada pelos autores

Priorização das Características Técnicas - Para se estabelecer o elo entre os dois mundos faz-se uso da sala de relacionamento. Por meio dos sinais e dos correspondentes valores, o elo é estabelecido e são calculados valores que nortearão o projetista. Ribeiro et al (2001) sugerem escala com símbolos (neste trabalho preferiu-se o uso de cores) e significado, iniciando por: fraca relação (cor verde, valor = 1); média relação ( cor amarela, valor = 3); forte relação (cor vermelha, valor $=9$ ). A Figura 3 mostra o resultado. 
Figura 3 - Exemplo de relacionamento entre Qualidade Exigida e Característica da Qualidade

\begin{tabular}{|c|c|c|c|c|c|c|c|c|c|c|c|}
\hline & & 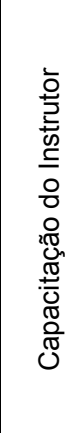 & 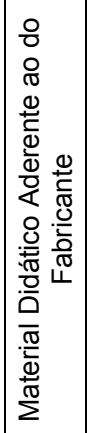 & 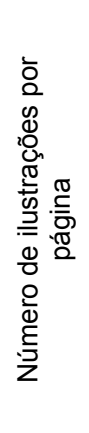 & 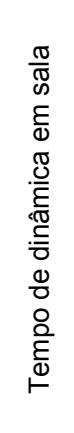 & 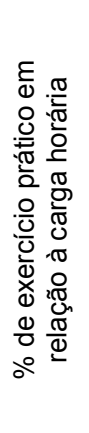 & 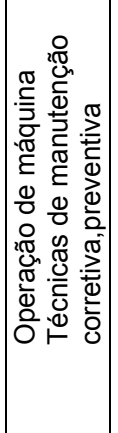 & 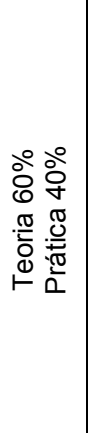 & 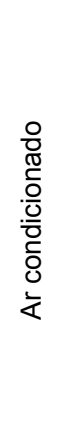 & 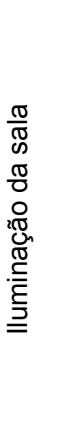 & 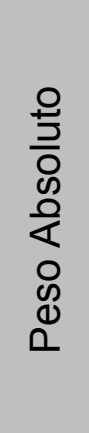 \\
\hline $\begin{array}{l}\text { Qualidade Exigida (Nível } \\
\text { 3) }\end{array}$ & Meta & $\uparrow$ & $=$ & $=$ & $\uparrow$ & $=$ & $=$ & $=$ & $=$ & $=$ & PA \\
\hline \multicolumn{2}{|c|}{$\begin{array}{l}\text { Instrutor transmite entusiasmo pelo } \\
\text { assunto }\end{array}$} & & & & & & & & & & 9,8 \\
\hline \multicolumn{2}{|c|}{ Instrutor esclarece bem as dúvidas } & & & & & & & & & & 4,7 \\
\hline \multicolumn{2}{|c|}{$\begin{array}{l}\text { Instrutor prende a atenção dos } \\
\text { participantes }\end{array}$} & & & & & & & & & & 2,4 \\
\hline \multicolumn{2}{|c|}{ Material de fácil entendimento } & & & & & & & & & & 6,1 \\
\hline \multicolumn{2}{|c|}{$\begin{array}{c}\text { Material que estimule maior } \\
\text { participação }\end{array}$} & & & & & & & & & & 2,6 \\
\hline \multicolumn{2}{|c|}{ Material de fácil utilização } & & & & & & & & & & 4,0 \\
\hline \multicolumn{2}{|c|}{$\begin{array}{c}\text { Material agradável aos quatro } \\
\text { sentidos }\end{array}$} & & & & & & & & & & 8,2 \\
\hline \multicolumn{2}{|c|}{ Conteúdo adequado } & & & & & & & & & & 3,9 \\
\hline \multicolumn{2}{|c|}{ Bom equilíbrio entre teoria e prática } & & & & & & & & & & 12,8 \\
\hline \multicolumn{2}{|c|}{$\begin{array}{c}\text { Boa distribuição das atividades do } \\
\text { curso }\end{array}$} & & & & & & & & & & 6,2 \\
\hline \multicolumn{2}{|c|}{ Ambiente com temperatura agradável } & & & & & & & & & & 3,0 \\
\hline \multicolumn{2}{|c|}{ Ambiente com boa iluminação } & & & & & & & & & & 3,6 \\
\hline \multicolumn{2}{|c|}{ Priorização Técnica } & 474 & $\begin{array}{c}32 \\
4\end{array}$ & $\begin{array}{c}15 \\
0\end{array}$ & 128 & 242 & 254 & $\begin{array}{c}29 \\
0\end{array}$ & 27 & 32 & \\
\hline
\end{tabular}

Fonte: Elaborada pelos autores

Para o cálculo do valor da Priorização Técnica é usado a equação $P_{t}=\sum_{i=n}^{n}\left(P_{a} F_{r}\right)$, onde

$P_{t}=$ Prioridade Técnica

$\mathrm{P}_{\mathrm{a}}=$ Peso absoluto da Qualidade Exigida

$F_{r}=$ Força de relação entre a Qualidade Exigida e a Característica da Qualidade

Para exemplificar veja o exemplo de cálculo para "capacitação do instrutor" 


$\begin{gathered}\text { Qualidade Exigida } \\ \text { (Nível 3) }\end{gathered}$
Instrutor transmite
entusiasmo pelo
assunto
Instrutor esclarece bem
as dúvidas
Instrutor prende a
atenção dos
participantes
Material de fácil
entendimento
Material que estimule
maior "participação"
Material de fácil
utilização
Material agradável aos
quatro sentidos
Conteúdo adequado
Bom equilíbrio entre
teoria x prática
Boa distribuição das
atividades do curso
Ambiente com
temperatura agradável
Ambiente com boa
iluminação

Força de Relacionamento com "Capacitação do Instrutor"
Peso Absoluto
Prioridade Técnica

$9,8 \quad \mathrm{Pt}=9 \times 9,8=88,2$

$4,7 \quad \mathrm{Pt}=9 \times 4,7=42,3$

2,4

6,1

2,6

4

8,2 $\quad \mathrm{Pt}=3 \times 8,2=24,6$

$3,9 \quad \mathrm{Pt}=3 \times 3,9=11,7$

6,2

$$
\mathrm{Pt}=9 \times 2,4=21,6
$$

$1 \mathrm{Pt}=9 \times 6,1=54,9$

$6 \mathrm{Pt}=9 \times 2,6=23,4$

$4 \quad \mathrm{Pt}=9 \times 4=36$

$\mathrm{Pt}=9 \times 12,8=115,2$

$\mathrm{Pt}=9 \times 6,2=55,8$

$3 \mathrm{Pt}=0 \times 3=0$

3,6

$$
\mathrm{Pt}=0 \times 3,6=0
$$

Soma dos produtos

473,3

Priorização das Características Técnicas Corrigidas - Esta é realizada por meio da correção da Prioridade Técnica. Para essa correção aplica-se o grau de dificuldade e a avaliação competitiva usando-se a fórmula proposta por Ribeiro et al (2001).

$P_{t}^{*}=P_{t} \sqrt{G_{d}} \sqrt{A_{c}}$, onde:

- $\mathrm{Pt}^{*}$ Prioridade Técnica Corrigida

- $P_{t}==$ Prioridade Técnica

- $\mathrm{G}_{\mathrm{d}}=$ Grau de Dificuldade (dificuldade de mudar as especificações das Características de Qualidade) - pode assumir valores de: muito difícil $=0$; difícil $=1 ;$ moderada $=1,5 ;$ e fácil $=2$

- $\mathrm{A}_{c}=$ Avaliação Competitiva (o produto ou serviço é comparado com a concorrência, considerando as Características de Qualidade) - pode assumir valores de: acima da concorrência $=0,5$; similar à concorrência $=1$; abaixo da concorrência $=1,5$; muito abaixo da concorrência $=2$.

Após capturar os dados e realizar os cálculos os resultados podem ser vistos na Figura 4 
Figura 4 - Resultado da Priorização Técnica Corrigida

\begin{tabular}{|c|c|c|c|c|c|c|c|c|c|}
\hline & 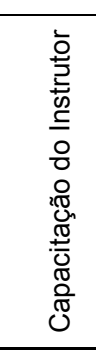 & 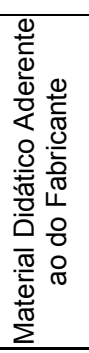 & 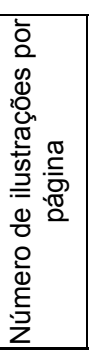 & 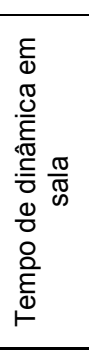 & 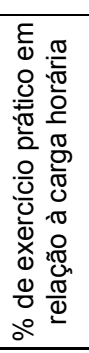 & 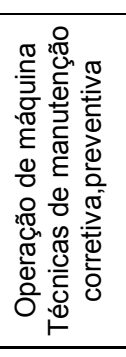 & 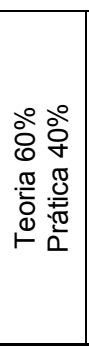 & $\begin{array}{l}\circ \\
\frac{0}{0} \\
\frac{0}{0} \\
\frac{0}{0} \\
\frac{0}{\overline{0}} \\
\overline{0} \\
0 \\
\dot{<}\end{array}$ & 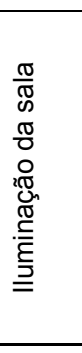 \\
\hline Priorização Técnica & 473 & 324 & 150 & 128 & 242 & 254 & 29 & 27 & 32 \\
\hline Grau de Dificuldade & 1 & 1,5 & 1 & 1,5 & 1 & 1 & 1 & 1 & 1,5 \\
\hline Avaliação Competitiva & 1 & 1,5 & 1,5 & 1 & 1,5 & 1,5 & 1,5 & 0,71 & 1 \\
\hline Prioridade Técnica & 473 & 486 & 18 & 157 & 296 & 310 & 35 & 19 & 40 \\
\hline
\end{tabular}

Fonte: Elaborada pelos autores

Uma vez tendo priorizado as Características Técnicas, é útil mostrá-las conforme Gráfico 1

Gráfico 1 - Priorização das Características da Qualidade (Exemplo de treinamento)

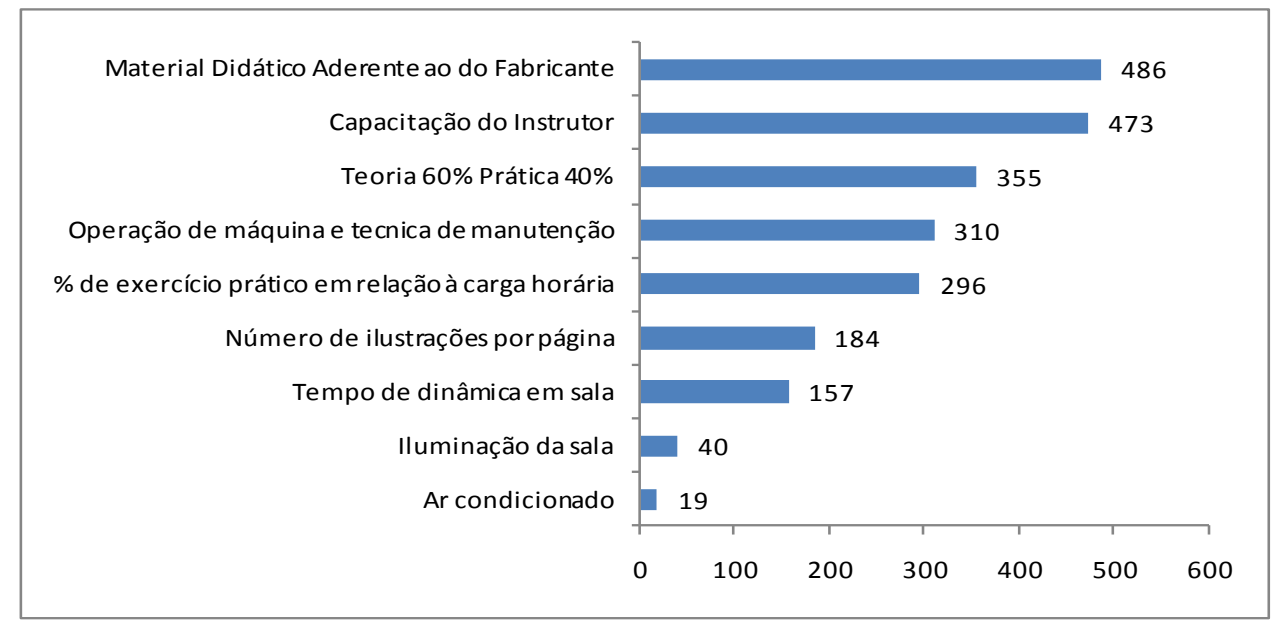

Fonte: Adaptado de Ribeiro et al (2001)

\section{PROCEDIMENTO METODOLÓGICO}

Este trabalho é classificado como pesquisa qualitativa - exploratória pois proporciona maior familiaridade com um problema, com vista a torná-lo mais explícito ou constituir hipóteses (GIL ,2009). Este tipo de estudo é realizado especialmente quando o tema escolhido é pouco explorado e torna-se difícil formular premissas precisas sobre um tema.

A classificação da pesquisa como exploratória é útil para o estabelecimento de marco teórico; entretanto, Gil (2009, p. 43) ressalta que "para analisar os fatos do 
ponto de vista empírico, para confrontar a visão teórica com dados da realidade, torna-se necessário traçar um modelo conceitual e operativo da pesquisa". Tal procedimento é comumente denominado de delineamento, como apresentado na Figura 5.

Definição do objeto e sujeito - como objeto definiu-se uma empresa de grande porte de prestação de serviço de TI. Como sujeitos, os técnicos de produção de serviços e analistas de treinamento.

Realização da pesquisa bibliográfica - pesquisa bibliográfica sobre os temas relacionados à pesquisa.

Construção da tabela das prováveis Qualidades Exigidas segundo Cheng (2007) - como os entrevistados não tinham familiaridade com os termos relacionados ao treinamento, foi proposta uma tabela das qualidades exigidas como ponto de partida.

Figura 5 - Método usado no desenvolvimento de um treinamento

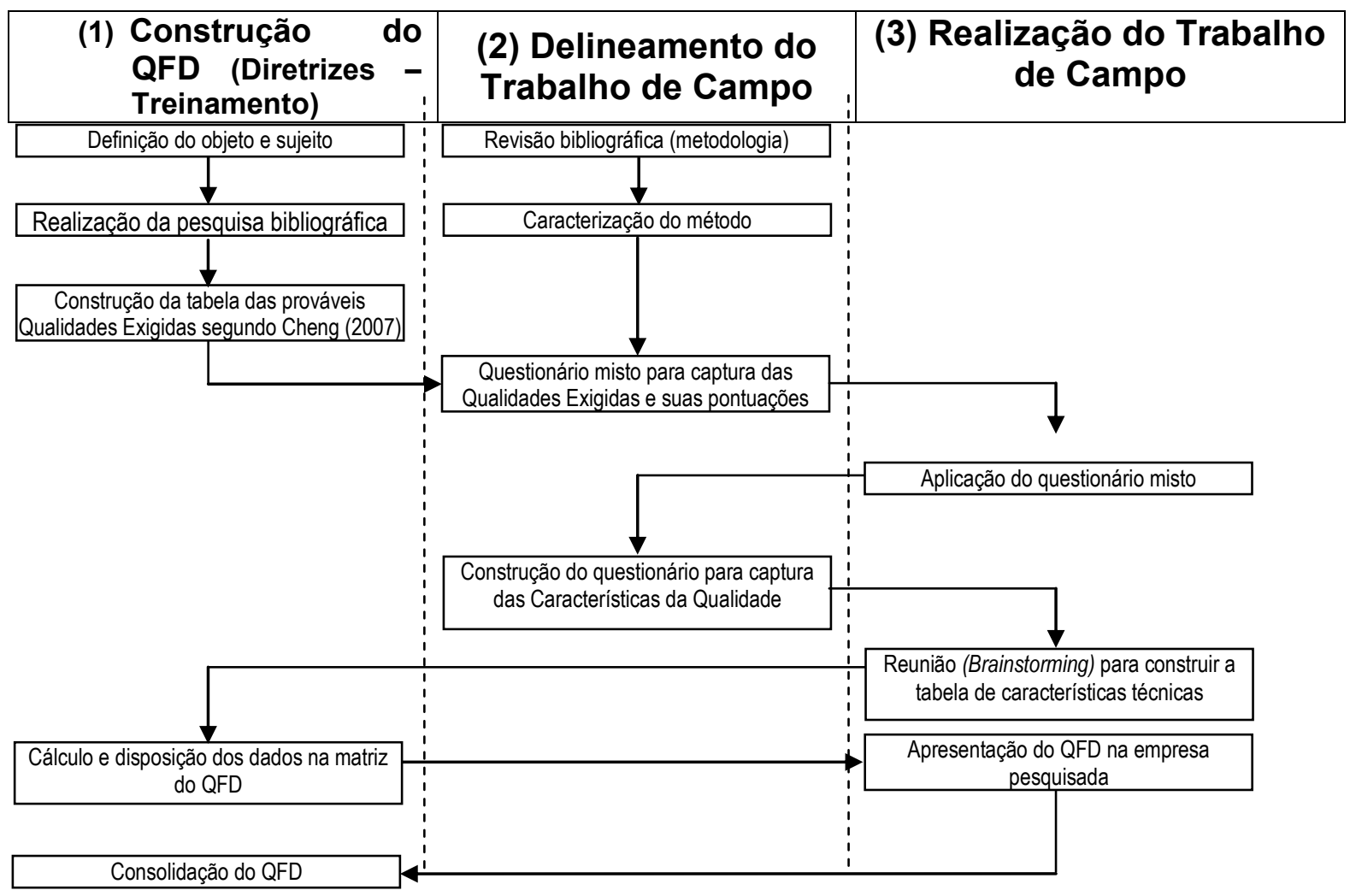

Fonte: Adaptado de Muniz (2009)

Revista Produção Online. Florianópolis, SC, v.12, n. 1, p. 91-118, jan./mar. 2012. 
Revisão bibliográfica (metodologia) - foi realizada uma revisão bibliográfica para a definição do método.

Instrumento de coleta, questões mistas (abertas e fechadas) - no mesmo instrumento de coleta de dados foi reservado espaço para os entrevistados registrarem outras qualidades exigidas. Visto que uma das limitações inerentes às questões abertas é a dificuldade de se tabularem dados, foi usado o diagrama de afinidades para criação de categorias, o que possibilitou o agrupamento em categorias já existentes ou a criação de novas.

Aplicação do questionário misto - os questionários foram aplicados nas dependências da empresa. Primeiramente, foi dado um minitreinamento para o entendimento do método de QFD. Nessa etapa, também foram capturadas as pontuações (escala de Likert) a serem usadas para quantificar a percepção do cliente.

Construção do questionário para captura das características da qualidade - de posse da tabela de Qualidade Exigida, foi construído outro instrumento de coleta para a captura das características da qualidade.

Reunião técnica com analistas de treinamento - realizou-se uma reunião específica com os analistas de treinamento incluindo uma sessão de brainstorming no sentido de: (a) capturar as características da qualidade que atendessem às Qualidades Exigidas; (b) estabelecer as metas de cada Característica da Qualidade; (c) construir a matriz de correlação ("telhado"); (d) estabelecer o grau de relacionamento entre as Qualidades Exigidas e as Características da Qualidade; (e) obter os demais itens numéricos para o cálculo da qualidade projetada.

Cálculo e disposição dos dados na matriz do QFD - os dados obtidos em etapas anteriores foram usados para se calcular à priorização das Qualidades Exigidas e se chegar à consolidação dos cálculos do Desdobramento da Qualidade.

Apresentação do QFD na empresa pesquisada - foi dada a chance para a empresa pesquisada apresentar críticas que são úteis para a consolidação do QFD. 
Consolidação do QFD - os apontamentos da etapa anterior são entradas para a consolidação do QFD.

\subsection{Perfil dos Entrevistados da Empresa Pesquisada}

A empresa pesquisada é de grande porte, com sua matriz na cidade de São Paulo, e iniciou atividades em 2002. Seu modelo de negócio consiste em comercializar soluções para geração, impressão e gestão de documentos. O Quadro 3 mostra as principais características da empresa. As Tabelas 2 e 3 trazem a caracterização da amostra.

Quadro 3 - Perfil da empresa pesquisada

\begin{tabular}{|c|c|c|c|c|}
\hline $\begin{array}{c}\text { Faturament } \\
\text { o anual }\end{array}$ & $\begin{array}{c}\text { Número de } \\
\text { funcionário } \\
\mathbf{s}\end{array}$ & Filiais & $\begin{array}{c}\text { Segment } \\
\text { o do } \\
\text { negócio }\end{array}$ & $\begin{array}{c}\text { Parceiro } \\
\text { tecnológico }\end{array}$ \\
\hline $\begin{array}{c}\mathrm{R} \$ \\
240.000 .00\end{array}$ & 1150 & $\begin{array}{c}\text { Rio de Janeiro, Belo } \\
\text { Horizonte, Brasília e Curitiba }\end{array}$ & $\begin{array}{c}\text { Serviço } \\
\text { de TI }\end{array}$ & $\begin{array}{c}\text { Ricoh corporation } \\
\text { (Japão) }\end{array}$ \\
\hline
\end{tabular}

Fonte: Autores

Foram dois grupos pesquisados: (a) técnicos de campo (grupo de clientes do treinamento), responsáveis pela produção de serviço da empresa; (b) analistas de treinamento (grupo de projetistas), responsáveis pela elaboração de plano de treinamento e aplicação deste. O perfil desses entrevistados é mostrado nas Tabelas 2 e 3, respectivamente.

Tabela 2 - Caracterização da amostra da empresa pesquisada (grupo de clientes)

\begin{tabular}{|c|c|c|c|c|c|c|}
\hline ID. & Cargo & $\begin{array}{c}\text { Formação } \\
\text { escolar }\end{array}$ & Concorrente & $\begin{array}{c}\text { Experiência } \\
\text { (anos) }\end{array}$ & $\begin{array}{l}\text { Idade } \\
\text { (anos) }\end{array}$ & $\begin{array}{c}\text { Tempo no cargo } \\
\text { na empresa } \\
\text { (anos) }\end{array}$ \\
\hline T1 & Técnico & $2^{\circ} \mathrm{Grau}$ Técnico & $A$ & 30 & 59 & 0,50 \\
\hline T2 & Técnico Jr. & $2^{\circ} \mathrm{Grau}$ Técnico & $B$ & 12 & 23 & 0,83 \\
\hline T3 & Técnico Jr. & Sup. Incompleto & B & 1,5 & 22 & 2,00 \\
\hline T4 & Técnico & $2^{\circ} \mathrm{Grau}$ Técnico & C & 10 & 39 & 1,08 \\
\hline T5 & Técnico & $2^{\circ}$ Grau Técnico & $\mathrm{D}$ & 23 & 43 & 0,08 \\
\hline T6 & Técnico & Sup. Incompleto & $E$ & 15 & 33 & 7,00 \\
\hline T7 & Técnico Jr. & $2^{\circ} \mathrm{Grau}$ Técnico & B & 3 & 25 & 2,00 \\
\hline T8 & Técnico Jr. & Sup. Incompleto & $B$ & 5 & 22 & 2,33 \\
\hline \multirow[t]{2}{*}{ T9 } & Técnico & $2^{\circ} \mathrm{Grau}$ Técnico & $\mathrm{B}$ & 9 & 27 & 0,50 \\
\hline & & & Média & 12,1 & 32,6 & 1,81 \\
\hline
\end{tabular}

Fonte: Autores 
A coluna "Concorrente" na Tabela 2 indica se o entrevistado trabalhou em alguma outra empresa do mesmo segmento ("A", "B", "C", "D" e “E”), isto é particularmente interessante, pois amplia a abrangência de conteúdo das repostas dos entrevistados e permite comparações, uma vez que os técnicos receberam nesses concorrentes, treinamentos semelhantes aos recebidos na empresa pesquisada. A análise da Tabela 2 indica que os técnicos têm experiência média de 12 anos nessa atividade, são relativamente jovens (32 anos) e estão há pouco tempo na empresa, um pouco mais de um ano e meio.

Tabela 3 - Caracterização da amostra da empresa pesquisada (grupo de projetistas)

\begin{tabular}{cccccc}
\hline ID & Cargo & Formação Escolar & $\begin{array}{c}\text { Experiência } \\
\text { (anos) }\end{array}$ & $\begin{array}{c}\text { Idade } \\
\text { (anos) }\end{array}$ & $\begin{array}{c}\text { Tempo no } \\
\text { cargo na } \\
\text { empresa (anos) }\end{array}$ \\
\hline A1 & Analista de treinamento Jr. & Sistema de Informação & 0,5 & 28 & 0,5 \\
A2 & Analista de treinamento & Psicologia & 9 & 54 & 1,5 \\
A3 & Analista de treinamento & Pós em Sistema de & 3 & 34 & 3 \\
A4 & Analista de treinamento Jr. & Sistema de Informação & 22 & 51 & 7 \\
\hline & & Média & $\mathbf{8 , 6}$ & $\mathbf{4 1 , 8}$ & $\mathbf{3 , 0}$ \\
\hline
\end{tabular}

Fonte: Autores

\section{RESULTADOS}

Pela lógica do método QFD, primeiramente foi coletada a voz do cliente, e em seguida, a voz do projetista, por fim são relatados os resultados das reuniões de consolidação.

\subsection{Resultados Relativos à Voz do Cliente}

A voz do cliente é formada por diversos itens, os quais foram obtidos por meio de formulário. Dos clientes (técnicos de campo) são: (a) grau de importância; (b) grau de desempenho; e (c) desempenho da concorrência. Da equipe interna de desenvolvimento de treinamento foram obtidos: (a) plano de qualidade e (b) argumento de venda. A partir dos dados, calculou-se o peso absoluto de cada qualidade exigida. Como exemplo veja o cálculo da qualidade exigida "instrutor transmite entusiasmo pelo assunto" $\mathrm{PA}=\mathrm{GI} . \mathrm{IM} . \mathrm{AV}=4,2$. 1,2 . 1,5=7,7. A figura 7 mostra os demais resultados. 
Segundo Sharma e Rawani (2007), se duas Características da Qualidade movem na mesma direção, elas são consideradas positivamente relacionadas. Similarmente, se uma Qualidade Exigida move em uma direção e a outra move em direção contrária, ou seja, tem um efeito diametralmente oposto, elas são consideradas negativamente relacionadas. Considerando esses dois efeitos, Sharma \& Rawani (2007) propõem quatro fatores assim representados: $(++)=1,50$ muito fortemente e positivamente relacionado; $(+)=1,25$ - fortemente $\mathrm{e}$ positivamente relacionado; $(--)=0,25$ - muito fortemente e negativamente (efeito oposto) relacionado; $(-)=0,50$ - fortemente e negativamente (efeito oposto) relacionado.

Figura 6 - Resultado do peso absoluto original

\begin{tabular}{|c|c|c|c|c|c|c|c|c|c|}
\hline Nível 1 & Nível 2 & Nível 3 & 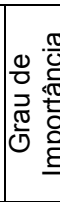 & 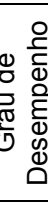 & & 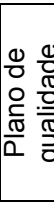 & & 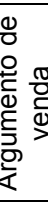 & 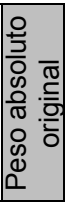 \\
\hline \multirow{10}{*}{$\begin{array}{l}1 \text { Ensino } \\
\text { eficaz }\end{array}$} & \multirow{3}{*}{ 1.1 Bom instrutor } & 1.1.1 Instrutor transmite entusiasmo pelo assunto & 4 , & 4 , & 4 & 5 & 1 , & 1, & 7 \\
\hline & & 1.1.2 Instrutor esclarece bem as dúvidas & 4, & 4 & 5 & 5 , & 1 , & 1, & 7 , \\
\hline & & 1.1.3 Instrutor prende a atenção dos participantes & 4 & 4 & 5 & 5 & 1 , & 1, & 7 , \\
\hline & \multirow{4}{*}{$\begin{array}{l}1.2 \text { Material didático de } \\
\text { boa qualidade }\end{array}$} & 1.2.1 Material de fácil entendimento & 3 & 3 & 5 & 5 , & 1 , & 1, & 8, \\
\hline & & 1.2.2 Material que estimule maior participação & 3 & 3 & 4 & 5 & 1, & 1, & 8 \\
\hline & & 1.2.3 Material de fácil utilização & 3 & 3 & 5, & 5 , & 1, & 1, & 7 , \\
\hline & & 1.2.4 Material agradável aos quatro sentidos & 3 & 3 & 5 & 4 & 1, & 1, & 5 \\
\hline & \multirow{3}{*}{$\begin{array}{l}1.3 \text { Bom conteúdo } \\
\text { programático }\end{array}$} & 1.3.1 Conteúdo adequado & 4 & 3 & 5 & 4 & 1, & 1, & 4 \\
\hline & & 1.3.2 Bom equilíbrio entre teoria e prática & 3 & 3 & 4, & 5 & 1, & 1, & 7 \\
\hline & & 1.3.3 Boa distribuição das atividades do curso & 3 & 3 & 5 & 4 & 1 , & 1, & 3 \\
\hline \multirow{2}{*}{$\begin{array}{l}2 \text { Aula } \\
\text { agradável }\end{array}$} & \multirow{2}{*}{$\begin{array}{l}2.1 \text { Ambiente físico } \\
\text { agradável aos quatro } \\
\text { sentidos }\end{array}$} & 2.1.1 Ambiente com temperatura agradável & $\begin{array}{l}3 \\
3\end{array}$ & 4, & 5, & 4 & $\begin{array}{l}0, \\
9\end{array}$ & 1, & $\begin{array}{l}3, \\
8\end{array}$ \\
\hline & & 2.1.2 Ambiente com boa iluminação & $\begin{array}{l}3 \\
6\end{array}$ & $\begin{array}{l}4, \\
0\end{array}$ & $\begin{array}{l}5, \\
0\end{array}$ & $\begin{array}{l}4, \\
0\end{array}$ & $\begin{array}{l}1, \\
0\end{array}$ & $\begin{array}{l}1, \\
2\end{array}$ & $\begin{array}{l}4 \\
3 \\
\end{array}$ \\
\hline
\end{tabular}

Fonte: Autores

As Qualidades Exigidas foram apresentadas para os analistas de treinamento no sentido de identificarem as sinergias entre elas. Todas as qualidades foram confrontadas entre si, o que resultou em um mapa, conforme a Figura 7.

Figura 7 - Mapa de sinergias entre as Qualidades Exigidas 


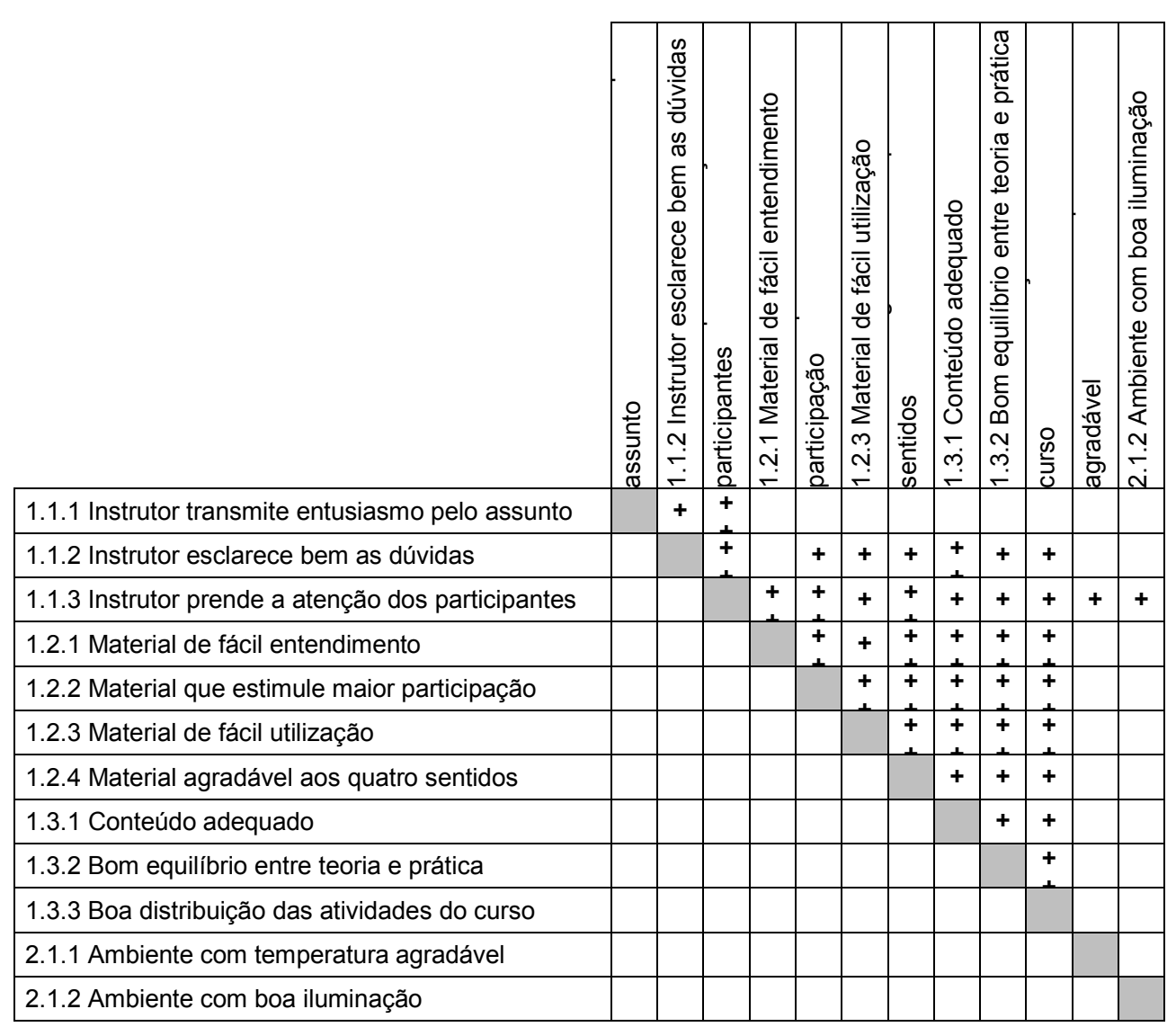

Fonte: Elaborado pelos autores

Desse modo, foi calculado um novo peso absoluto que leva em conta as sinergias entre as qualidades exigidas. O cálculo é feito usando o algoritmo de Sharma e Rawani (2007). O resultado é mostrado na Tabela 4, e os destaques são:

- As qualidades exigidas que sofreram reforço foram: (a) "1.1.3 Instrutor prende a atenção dos participantes" 107\% (era 7,71 e passou a ser 15,95); (b) "1.1.2 Instrutor esclarece bem as dúvidas" $45 \%$ (era 7,68 e passou a ser 12,56); (c) "1.2.1 Material de fácil entendimento" $55 \%$ (era 8,75 e passou a ser 13,56); (d) "1.2.2 Material que estimule maior "participação" 35\% (era 8,04 e passou a ser 10,81); (e) "1.2.3 Material de fácil utilização" $10 \%$ (era 7,25 e passou a ser 7,99 ). 
Tabela 4 - Resultado do peso absoluto corrigido pelo algoritmo de Sharma e Rawani (2007)

\begin{tabular}{|c|c|c|c|c|c|}
\hline Qualidade Exigida & $\begin{array}{c}\text { Peso } \\
\text { absoluto } \\
\text { original }\end{array}$ & $\begin{array}{l}\text { Peso } \\
\text { relativo }\end{array}$ & $\begin{array}{l}\text { Ponderador } \\
\text { Intermediário }\end{array}$ & $\begin{array}{c}\text { Novo } \\
\text { peso } \\
\text { relativo }\end{array}$ & $\begin{array}{c}\text { Peso } \\
\text { absoluto } \\
\text { corrigido }\end{array}$ \\
\hline 1.1.1 Instrutor transmite entusiasmo pelo assunto & 7,7 & 0,10 & 0,40 & 0,06 & 4,60 \\
\hline 1.1.2 Instrutor esclarece bem as dúvidas & 7,7 & 0,10 & 1,10 & 0,16 & 12,56 \\
\hline 1.1.3 Instrutor prende a atenção dos participantes & 7,7 & 0,10 & 1,40 & 0,21 & 15,95 \\
\hline 1.2.1 Material de fácil entendimento & 8,8 & 0,11 & 1,19 & 0,18 & 13,56 \\
\hline 1.2.2 Material que estimule maior participação & 8,0 & 0,10 & 0,95 & 0,14 & 10,81 \\
\hline 1.2.3 Material de fácil utilização & 7,3 & 0,09 & 0,70 & 0,10 & 7,99 \\
\hline 1.2.4 Material agradável aos quatro sentidos & 5,8 & 0,08 & 0,38 & 0,06 & 4,31 \\
\hline 1.3.1 Conteúdo adequado & 4,9 & 0,06 & 0,24 & 0,03 & 2,70 \\
\hline 1.3.2 Bom equilíbrio entre teoria e prática & 7,5 & 0,10 & 0,25 & 0,04 & 2,86 \\
\hline 1.3.3 Boa distribuição das atividades do curso & 3,6 & 0,05 & 0,05 & 0,01 & 0,54 \\
\hline 2.1.1 Ambiente com temperatura agradável & 3,8 & 0,05 & 0,05 & 0,01 & 0,56 \\
\hline 2.1.2 Ambiente com boa iluminação & 4,3 & 0,06 & 0,06 & 0,01 & 0,63 \\
\hline Total & 77,1 & 1,00 & 6,74 & 1,00 & 77,06 \\
\hline
\end{tabular}

Fonte: Elaborada pelos autores

- As demais qualidades exigidas sofreram uma diminuição natural do algoritmo de Sharma \& Rawani (2007), pois o valor total não pode variar; portanto, se várias Qualidades Exigidas sofrem reforços, outras devem diminuir sua intensidade.

Figura 8 - Efeito da correção pelo algoritmo de Sharma e Rawani (2007)

\begin{tabular}{lcc}
\hline \multicolumn{1}{c}{ Qualidade Exigida } & $\begin{array}{c}\text { Peso } \\
\text { absolu } \\
\text { to } \\
\text { origina } \\
\text { I }\end{array}$ & $\begin{array}{c}\text { Classi } \\
\text { ficaçã } \\
\text { oOrigi } \\
\text { nal }\end{array}$ \\
\hline 1.2.1 Material de fácil entendimento & 8,8 & I \\
1.2.2 Material que estimule maior & 8,0 & II \\
1.1.3 Instrutor prende a atenção dos & 7,7 & III \\
1.1.1 Instrutor transmite entusiasmo pelo & 7,7 & IV \\
1.1.2 Instrutor esclarece bem as dúvidas & 7,7 & $\mathrm{~V}$ \\
1.3.2 Bom equilíbrio entre teoria e prática & 7,5 & VI \\
1.2.3 Material de fácil utilização & 7,3 & VII \\
1.2.4 Material agradável aos quatro & 5,8 & VIII \\
1.3.1 Conteúdo adequado & 4,9 & IX \\
2.1.2 Ambiente com boa iluminação & 4,3 & $\mathrm{X}$ \\
2.1.1 Ambiente com temperatura & 3,8 & $\mathrm{XI}$ \\
1.3.3 Boa distribuição das atividades do & 3,6 & $\mathrm{XII}$ \\
\hline
\end{tabular}

\begin{tabular}{ccc}
\cline { 2 - 3 } & $\begin{array}{c}\text { Peso } \\
\text { absolu } \\
\text { to } \\
\text { corrigi } \\
\text { do }\end{array}$ & $\begin{array}{c}\text { Nova } \\
\text { Classi- } \\
\text { ficação }\end{array}$ \\
\hline 13,56 & II \\
& 10,81 & IV \\
& 15,95 & I \\
Após o & 4,60 & VI \\
algoritmo de & 12,56 & III \\
Sharma e & 2,86 & VIII \\
Rawani & 7,99 & V \\
& 4,31 & VII \\
& 2,70 & IX \\
& 0,63 & X \\
& 0,56 & XI \\
& 0,54 & XII \\
\hline
\end{tabular}

Fonte: Elaborada pelos autores

- A Figura 8 evidencia o efeito da aplicação do algoritmo de Sharma e Rawani (2007), em que as Qualidades Exigidas foram reclassificadas usando como fator classificatório "Peso absoluto original" à esquerda e "Peso absoluto corrigido" à direita. 


\subsection{Resultados Relativos à Voz do Projetista}

A captura da voz do projetista foi obtida a partir de reuniões com sessões de brainstorming e discussões, das quais se obtiveram: (a) tabela de Características da Qualidade (incluindo as metas); (b) grau de relacionamento entre as Qualidades Exigidas e as Características da Qualidade; (c) definição de metas técnicas; (d) cálculo da priorização técnica; (e) avaliação competitiva das Características da Qualidade; (f) levantamento do grau de dificuldade para atuar na Característica da Qualidade; e (g) cálculo da priorização técnica corrigida.

Uma vez que o QFD estabelece a relação entre dois mundos - do cliente e do projetista - é necessário extrair as Características da Qualidade a partir das Qualidades Exigidas. Procedendo desta forma, obtiveram-se inicialmente 83 características da qualidade; após análise crítica realizada pela equipe de analistas de treinamento, resultaram 51. No segundo momento, aplicou-se o diagrama de afinidade, o que resultou em 33 características da qualidade. A Figura 9 mostra a sequência adotada.

Figura 9 - Processo para obtenção das características da qualidade

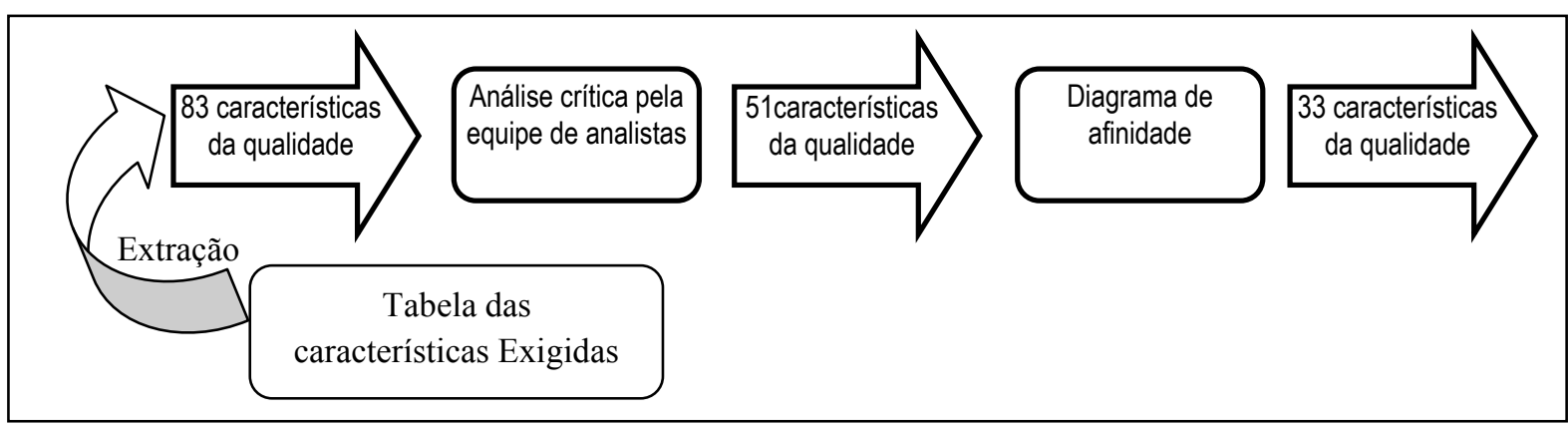

Fonte: Elaborada pelos autores

Os resultados referentes à voz do projetista foram consolidados na Figura 10 . Os símbolos usados para quantificar o grau de relacionamento tiveram seus valores atribuídos conforme segue: vermelho: forte relação $=9$; amarelo: média relação $=3$; verde: fraca relação $=1$. 
Figura 10 - Resultados consolidados do QFD

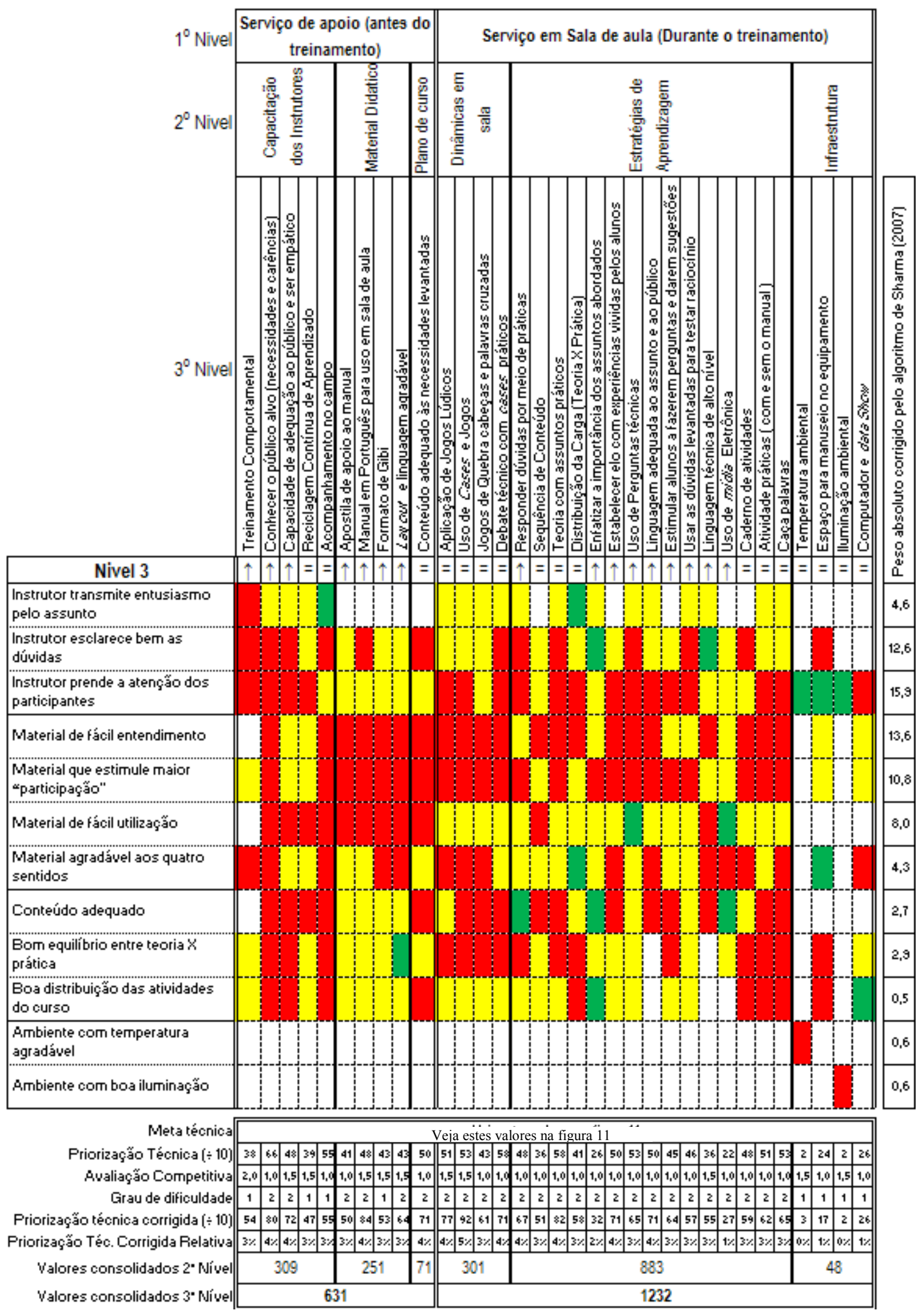

Fonte: Elaborada pelos autores

Revista Produção Online. Florianópolis, SC, v.12, n. 1, p. 91-118, jan./mar. 2012. 
As metas técnicas das características da qualidade que puderam ser quantificadas são mostradas na Figura 11.

Figura 11 - Metas técnica das características da qualidade mensuráveis

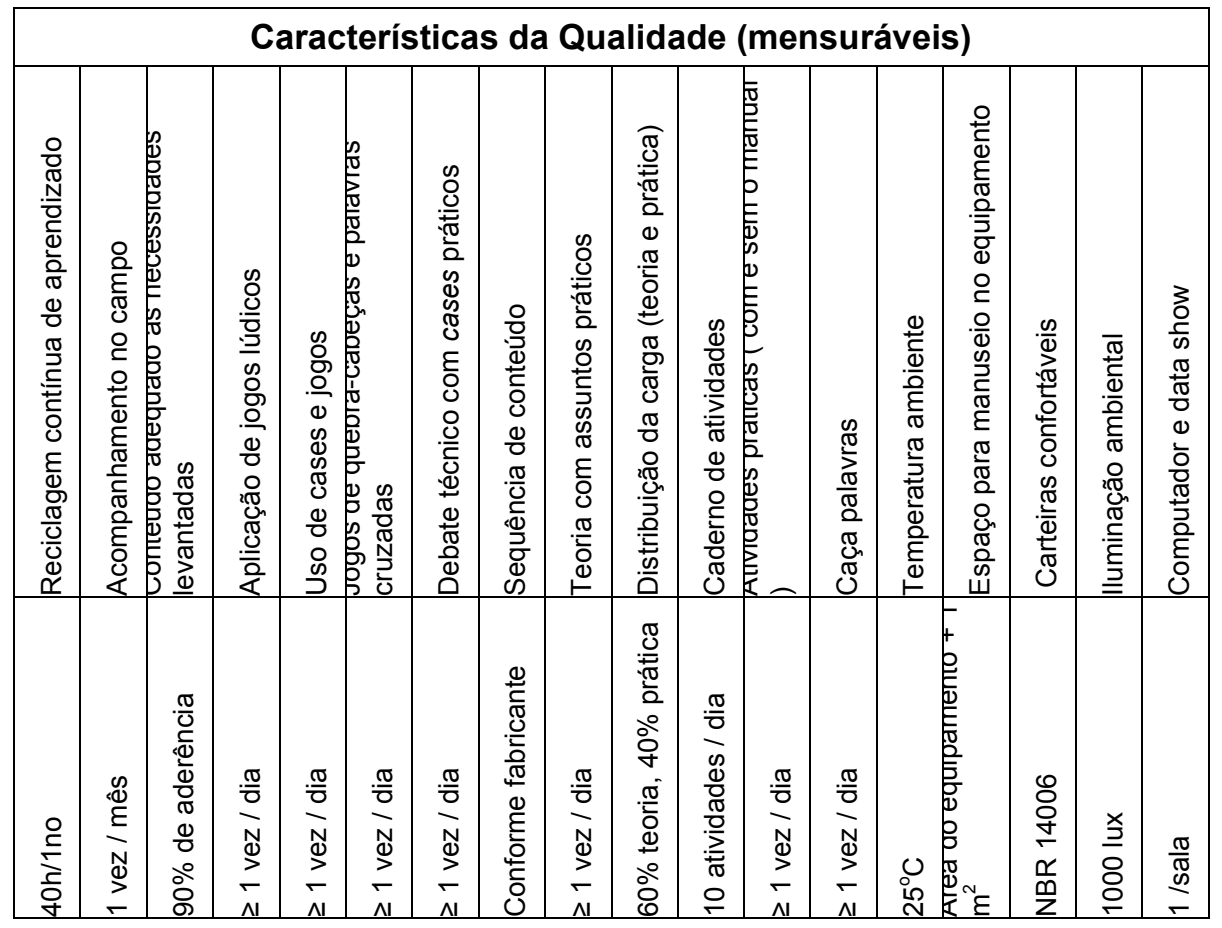

Fonte: Elaborada pelos autores

Para os projetistas, ter as Características de Qualidade em detalhes auxilia nas ações pontuais, entretanto para ter uma visão geral ou gerencial é útil agrupálas - neste caso Níveis 1 e 2 - pois desta forma a visão é mais ampla e pode tomar decisões de âmbito mais geral. Ao consolidar desta forma se obtiveram os resultados mostrados na parte inferior da Figura 10, que foram expressos no Gráfico 2 (a e b) 
Gráfico 2 - Priorização consolidada das características da qualidade

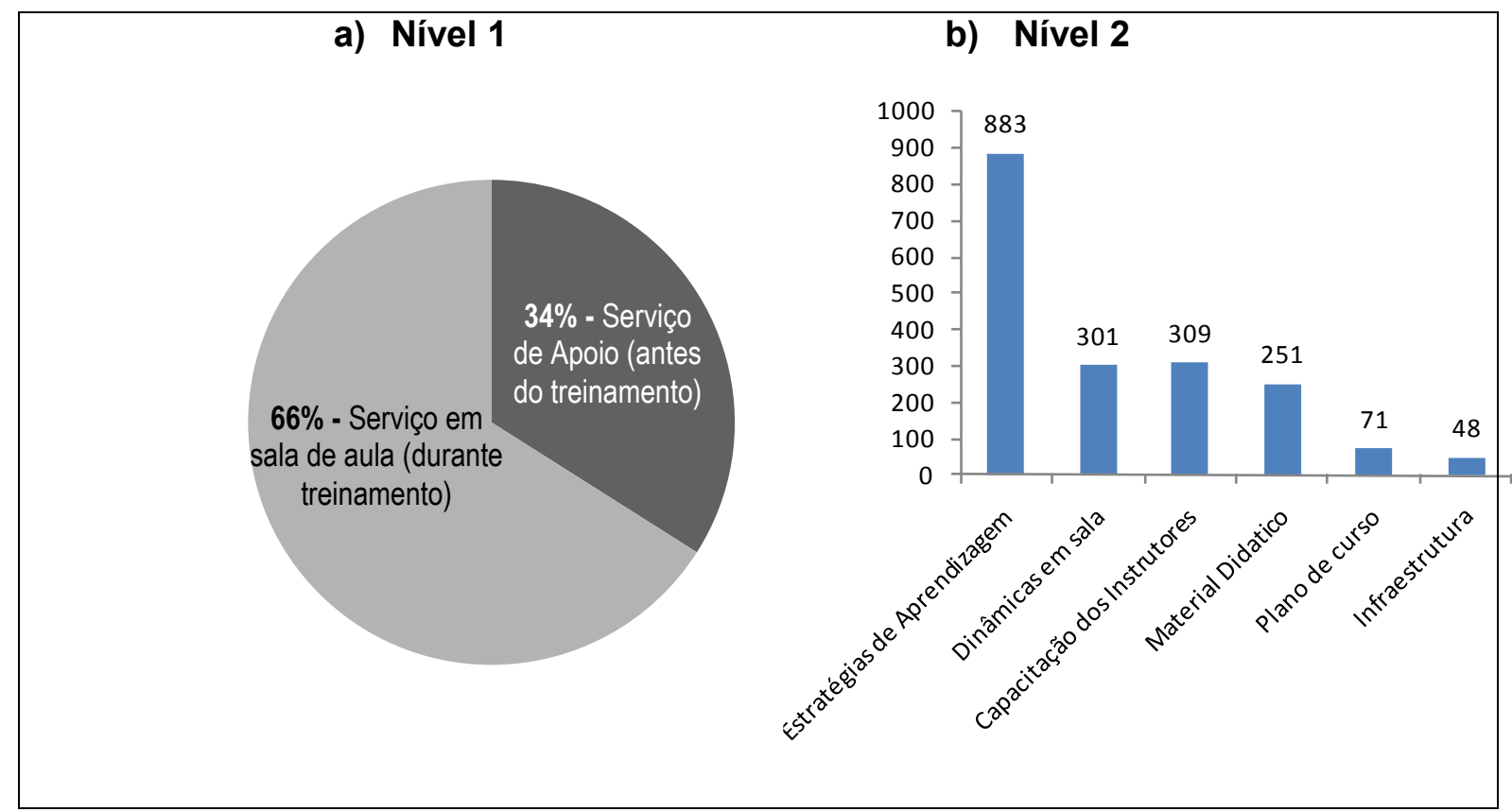

Fonte: Elaborada pelos autores

\subsection{Resultados da Reunião de Consolidação}

$\mathrm{Na}$ apresentação dos resultados foi possível identificar argumentos que auxiliaram na consolidação do roteiro, bem como foram tiradas dúvidas dos envolvidos da empresa.

As seguintes citações, dos analistas de treinamento, ilustram tal fato: “... achei interessante o processo de transformar as necessidades dos clientes em atividades exercidas por nós”. Complementada em seguida: “... é uma forma interessante de documentar um desenvolvimento de treinamento".

A apresentação dos resultados em um único documento (QFD completo) deu à equipe de analistas a visão geral e consolidada de todo o trabalho realizado. Outra citação ilustra esta constatação: “... ser possível visualizar em um único documento os resultados da pesquisa foi o que mais me chamou a atenção".

Desse modo, com respeito aos resultados da priorização das características da qualidade ficou evidente a utilidade conforme a citação: “... os top 5 [cinco itens prioritários, nota do autor] realmente fazem sentidos”, reforçada por: “... acredito que se atuarmos pelo menos nas cinco características da qualidade mais importantes, já teremos um grande avanço". 
Vale ressaltar ainda que, como foi citada, a chefia imediata tem interesse em implantar o QFD, mas que poderão existir dificuldades por parte da empresa, talvez por se tratar de um método ainda desconhecido na cultura da empresa. A seguinte citação evidencia tal preocupação: “... seria interessante que a gerência conhecesse também para ser possível as mudanças necessárias".

Com base neste último comentário, fica evidente que o método é útil para os analistas que participaram da pesquisa, entretanto é necessário que outros setores da empresa tenham o conhecimento dele para torná-lo um método aceito.

\section{CONCLUSÕES}

O presente trabalho apresentou a utilização do método QFD para o desenvolvimento de projeto de treinamento. A pesquisa identificou com os principais clientes de treinamento (técnicos de campo) as principais características necessárias ao treinamento para que os analistas de treinamento (projetistas) se orientassem.

Registra-se que normalmente a sistematização de serviços, neste caso treinamento, se apresenta como uma dificuldade intrínseca devido a sua intangibilidade.

O agrupamento das Características da Qualidade permitiu dividir em dois grandes grupos e constatar a valoração assim distribuída:

a) Nível 1 - serviço de apoio antes do treinamento (34\%) e serviço em sala de aula durante o treinamento $(66 \%)$ - com este resultado do Nível 1 evidencia-se que os clientes valorizam as atividades em sala num primeiro momento;

b) Nível 2 - os itens "estratégias de aprendizagem", "dinâmicas em sala" e "capacitação dos instrutores" somam $80 \%$ do total da pontuação ficando $20 \%$ para outros 3 itens ("material didático", "plano de curso" e "infraestrutura"). Os três itens, do Nível 2, mais relevantes reforçam o que foi constatado no Nível 1, pois 2 itens, "estratégias de aprendizagem" e "dinâmicas em sala", pertencem ao serviço em sala de aula durante o treinamento.

A reunião para apresentação dos resultados se mostrou efetiva para a consolidação de conceitos e o planejamento das ações necessárias para o atendimento dos requisitos dos clientes. 
O método adotado pode ser generalizado e os resultados obtidos orientam pesquisadores e gestores a desenvolverem projeto de serviços em situações semelhantes.

Este trabalho pode ser considerado um complemento ao trabalho Chou (2004), pois usou o algoritmo de Sharma e Rawani (2007) como forma de ponderar as interações entre as necessidades do cliente. Enquanto Chou (2004) enfatizou o tamanho da amostra, este trabalho visou obter dados de uma amostra menor, mas composta por pessoas que tivessem vivenciado o serviço de treinamento em outras empresas.

Como proposta de trabalho futuro, os autores pretendem pesquisar o uso do QFD no projeto de curso de graduação noturno em Instituição de Ensino Superior (IES) privadas, pois este público apresenta necessidades particulares em relação às públicas.

\section{REFERÊNCIAS}

ABBAD, G. e PILATI, R. Análise fatorial confirmatória da escala de impacto do treinamento no trabalho. Psicologia: Teoria e Pesquisa, Brasília, v. 21, n. 1, p.4351, jan./abr. 2005.

ASSOCIAÇÃO BRASILEIRA DE NORMAS TÉCNICAS. NBR ISO 10015 - gestão da qualidade: diretrizes para treinamento. Rio de Janeiro: ABNT, 2001.

BONFIM, D. F. Pedagogia no treinamento. 2.ed. Rio de Janeiro: Qualimark, 2004.

CAMPOS, J. P. \& GUIMARÃES, S.. Em busca da eficácia em treinamento. [S.I.]: s.n.], 2008. Disponível em: <http://www.abacocursos.com.br/download/e-book.pdf>. Acesso em: 15 jan. 2009.

CARNEVALLI, José Antonio; e MIGUEL, Paulo Augusto Cauchick. Revisão, análise e classificação da literatura sobre o QFD: tipos de pesquisa, dificuldades de uso e benefícios do método. Gestão \& Produção, São Carlos, v.14, n. 3, p. 557-579, set./dez., 2007,

CELLETTI, F; WRIGHT, A; PALEN, J; FREHYWOT, S; MARKUS, A; GREENBERG, A; DE AGUIAR, R.A.T; CAMPOS, F; BUCH, E; SAMB, B. Can the deployment of community health workers for the delivery of HIV services represent an effective and sustainable response to health workforce shortages? Results of a multicountry study. AIDS, v. 24, p.45-57, jan. 2010.

CHENG, L.C. (Coord.). QFD: desdobramento da função qualidade na gestão de desenvolvimento de produtos. São Paulo: Editora Blücher, 2007. 
$\mathrm{CHOU}$, S.M. Evaluating the service quality of undergraduate nursing education in Taiwan - using quality function deployment. Nurse Education Today, v. 24, Issue 4, p. 310-318, maio 2004 .

DRUCKER, P. F. O melhor de Peter Drucker: o homem. São Paulo: Nobel, 2002.

ENGELKE, U; KUSUMA, M; ZEPERNICK, HJ; CALDERA, M. Reduced-reference metric design for objective perceptual quality assessment in wireless. Signal Processing -Image Communication, v. 24, Issue 7, p. 525-547, ago. 2009.

GIANESI, I. G. N. e CORREAA, H. J. Administração estratégica de serviços. São Paulo: Atlas, 1996.

GUINTA, L. R. \& PRAIZLER, N. C. Manual do QFD: o uso de equipes para problemas e satisfazer clientes pelo desdobramento da função qualidade. Rio de Janeiro: L.T.C., 1993.

JUSTHAN, L; WEST, A.A. Use of the quality function deployment methodology in the development of a novel training system for cricket. Proceedings of the Institution of Mechanical Engineers Part P-Journal of Sports Engineering and Technology, v. 222, Issue: P2, p. 103-112, dez, 2008.

KOTLER, P. Administração de marketing: análise, planejamento, implementação e controle. 5. ed. São Paulo: Atlas, 1998.

KUO, R.J. et al. Improving outpatient services for elderly patients in Taiwan: A qualitative study. Archives of Gerontology and Geriatrics, v. 53, Issue: 2, p. 209217, set./out. 2011.

LEE, S.F.; LO, K.K. Enterprise and management course development using strategy formulation framework for vocational education. Journal of Materials Processing Technology, v. 139, Issue: 1-3, p. 604-612, ago. 2003.

LICK, C.J; AUFDERHEIDE, T.P; NISKANEN, R.A; STEINKAMP, J.E; DAVIS, S.P; NYGAARD, S.D; BEMENDERFER, K.K; GONZALES, L; KALLA, J.A; WALD, S.K; GILLQUIST, D.L; SAYRE, M.R; HOLM, S.Y.O; OAKES, D.A; PROVO, T.A; RACHT, E.M; OLSEN, J.D; YANNOPOULOS, D; LURIE, K.G. Take Heart America: A comprehensive, community-wide, systems-based approach to the treatment of cardiac arrest. Critical Care Medicine, v. 39, Issue: I, p. 26-33, jan. 2011.

MUNIZ, J.; BATISTA JR. E. D.; TRZESNIAK P.; e MARINS, F. A. S. Fundamentos para construção de modelos conceituais de gestão de produção. In: OLIVEIRA, V. F.; CAVENAGUI, V.; MÁSCULO, F. S. (Org.). Tópicos emergentes e desafios metodológicos em engenharia de produção: casos, experiências e proposições. $v$ II. Rio de Janeiro/RJ: Associação Nacional de Engenharia de Produção, p. 26-33, 2009. 
RIBEIRO, J. L. D.; ECHEVESTE, M. E. e DANILEVICZ, A. M. F. A utilização do qfd na otimização de produtos, processos e serviços. Porto Alegre/RS:

FEENG/PPGEP/EE/ UFRGS, 2001.

SHARMA, J. R. e RAWANI, A.M. Ranking customer requirements in qfd by factoring in their interrelationship value.The Quality Management Journal, S.I., v. 14, n. 4, p. 53-60, abr. 2007.

TAPKE, J. ; MULLER, A. e SIEK, J. House of quality: steps in understanding the house of quality, I E 361, S.I., 2009. Disponível em:

<http://www.public.iastate.edu/ vardeman/IE361/ f01mini/johnson.pdf>. Acesso em: 9 nov. 2009.

WOODFORD, J.D. Synergies between veterinarians and para-professionals in the public and private sectors: organizational and institutional relationships that facilitate the process of privatizing animal health services in developing countries. Revue Scientifique et Technique del Office International des Epizooties, v. 23, Issue: 1, p. 115-135, abr. 2004

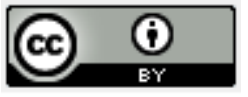

Artigo recebido em 04/08/2010 e aceito para publicação em 22/12/2011. 